Revista Bioética

\title{
EDITORIAL
}

\section{Bioética: bússola para guiar nosso caminho}

Tatiana Bragança de Azevedo Della Giustina ${ }^{1}$, Rui Nunes ${ }^{2}$

1. Conselho Federal de Medicina, Brasília/DF, Brasil. 2. Universidade do Porto, Porto, Portugal

Iniciamos esta edição com o tema que tem dominado as discussões sobre saúde no mundo: a tomada de decisão durante a pandemia de covid-19. As condições impostas pelo aumento da demanda por serviços de saúde e o ainda vasto desconhecimento acerca dessa nova doença trazem à prática clínica inevitáveis dilemas. Ter de escolher quem será priorizado em unidades de terapia intensiva, dada a escassez de leitos, ainda que apoiados por protocolos e resoluções, gera certa intranquilidade, na incerteza de saber se agimos corretamente ou não. Sejam as decisões tomadas com base na deontologia ou no utilitarismo, por exemplo, sabemos que ambos os caminhos têm limitações e terão impacto profundo na sociedade. Exatamente por isso, a bioética segue como caminho seguro e útil para quem está na linha de frente.

Os princípios éticos serão nossa bússola em relação às melhores decisões, que resguardem os direitos e a dignidade dos doentes, principalmente os mais vulneráveis ${ }^{1,2}$. De fato, se a ética hipocrática continua essencial para a relação clínica ao afirmar o primado da plena dedicação dos médicos a seus pacientes, outros valores, como justiça, integridade e respeito pela autonomia pessoal, são também fundamentais. Torna-se então necessário, na perspectiva pós-moderna de Beauchamp e Childress ${ }^{1}$, que o altruísmo e a solidariedade, que sempre caracterizaram a medicina, evoluam para nova aliança terapêutica respeitando a autodeterminação individual.

A integridade científica de pesquisas sobre covid-19 também será discutida, partindo do dramático cenário de pressões na comunidade científica para produzir conhecimento e obter, de forma imediata, tratamentos e soluções para o manejo da patologia, ainda pouco conhecida. Neste caminho, em que devem prevalecer a ética e a seriedade, circulam conflitos de interesse que podem invalidar pesquisas e trabalhos científicos se não forem aplicados critérios éticos rigorosos para proteger a vida e avaliar a vulnerabilidade dos participantes.

De acordo com Santos e Perez ${ }^{3}$, estes questionamentos, relacionados a agências de fomento, universidades, publicações científicas, pesquisadores, indústria farmacêutica e governos, têm sido debatidos há algum tempo. Para Faria ${ }^{4}$, a proximidade da ciência com a indústria farmacêutica e pressões políticas podem interferir no processo de investigação. Exemplo disso foi a questão envolvendo The Lancet, um dos mais importantes periódicos científicos, que entre suas muitas publicações teve que se retratar e remover um artigo de sua coleção ${ }^{4}$.

No contexto da pandemia de covid-19, o dever de tratar torna-se questão complexa. De acordo com Carvalho e Aguiar ${ }^{5}$, os médicos atendem os pacientes, mas surgem novos dilemas: a falta ou insuficiência de equipamento de proteção individual para exercer o trabalho geram perigo de contaminação para profissionais e seus familiares. $O$ estresse gerado pela escassez de recursos é ainda intensificado pelo testemunho de inúmeras mortes de pacientes e colegas. Normalmente, o médico aceita os riscos impostos a seu trabalho, mas tais riscos podem interferir na questão da saúde pública.

\section{Bíoética}

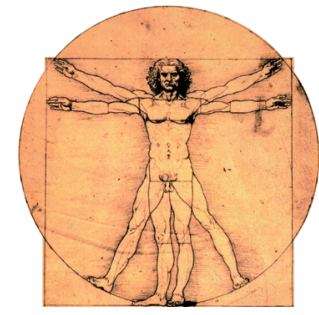


Entre outros temas abordados nesta edição, são discutidos aspectos legais e éticos de cirurgias de feminização facial em transexuais. De acordo com Silva Junior $^{6}$, tais procedimentos têm se tornado bastante populares entre travestis e mulheres transexuais, dado que diminuem o estigma e auxiliam a integração social.

A questão ambiental é também abordada neste fascículo. Para Fischer e colaboradores ${ }^{7}$, a aceleração do desenvolvimento tecnológico alterou profundamente a ecologia global, exigindo mudanças no padrão ético das relações humanas com a natureza, de forma a possibilitar a sobrevivência de nossa espécie.

Os artigos "Eutanásia sob a perspectiva da bioética e clínica ampliada" e "Potência spinoziana: resistência ao controle sobre o modo de morrer" tratam da terminalidade da vida e da autonomia dos pacientes nesse contexto. As resoluções do Conselho Federal de Medicina $1.805 / 2006^{8}$ e 1.995/2012 ${ }^{9}$, além do Código de Ética Médica ${ }^{10}$, dispõem sobre o tema, instruindo médicos acerca do delicado processo de morte.

Este exemplar também trata do vínculo que se estabelece na relação médico-paciente, explicitado na confiança e nos aspectos deontológicos e reflexivos dessa interação. Para Cassell ${ }^{11}$, a tarefa da medicina no século XXI será a descoberta da pessoa, isto é, verificar as origens da doença e do sofrimento e, a partir deste conhecimento, desenvolver métodos para aliviar a dor, desnudando o poder do próprio indivíduo.

Na perspectiva ricoeuriana, a relação contratual médica envolve diversos paradoxos: a pessoa humana não é objeto, mas seu corpo é observável como natureza física; embora a medicina não seja atividade mercantilista, tem preço e custos para a sociedade; e apesar de o sofrimento ser privado, a saúde é pública. Na função reflexiva do juízo deontológico, cada sociedade tem sua forma de integrar o sofrimento e a aceitação da mortalidade na ideia que se faz do que é felicidade ${ }^{12}$.

Finalmente, no artigo "Secularismo, pós-modernidade e justiça na assistência à saúde em Engelhardt" será discutida a dificuldade do projeto filosófico moderno e da pluralidade e tolerância no convívio da área de saúde. Segundo Madrid ${ }^{13}$, em suas propostas Engelhardt prevê uma ética global, que aceite a diversidade e o multiculturalismo. Libertário, Engelhardt ${ }^{14}$ também questiona o dever do Estado na assistência à saúde, no que concerne à questão de justiça e equidade na alocação de recursos.

Estes e outros interessantes temas e artigos de pesquisa estão à disposição de nossos leitores. Aproveitem uma excelente leitura!

Os editores

\section{Referências}

1. Beauchamp T, Childress J. Principles of biomedical ethics. 8a ed. Nova York: Oxford University Press; 2019.

2. Schramm FR, Palácios M, Rego S. O modelo bioético principialista para a análise da moralidade da pesquisa científica envolvendo seres humanos ainda é satisfatório? Ciênc Saúde Coletiva [Internet]. 2008 [acesso 21 ago 2020];13(2):361-70. DOI: 10.1590/S1413-81232008000200011

3. Santos LH, Perez JF. Conflito de interesses: um desafio inevitável. Pesqui Fapesp [Internet]. 2001 [acesso 21 ago 2020];(62). Disponível: https://bit.ly/2ELpQFT

4. Faria R. Ciência à medida: conflitos de interesse e interferência na investigação científica financiada. Sociologia [Internet]. 2018 [acesso 21 ago 2020];36:97-118. DOI: 10.21747/08723419/soc36a5

5. Carvalho S, Aguiar LA. Limites da responsabilidade na omissão de socorro às vítimas da covid- 19 . ConJur [Internet]. Opinião; 11 maio 2020 [acesso 20 ago 2020]. Disponível: https://bit.ly/31BKYaT

6. Silva AL Jr. Feminização, estigma e o gênero facializado: a construção moral do gênero feminino por meio de cirurgias de feminização facial para travestis e mulheres transexuais. Saúde Soc [Internet]. 2018 [acesso 21 ago 2020];27(2):464-80. DOI: 10.1590/s0104-12902018170771 
7. Fischer ML, Cunha $T$, Renk V, Sganzerla $A$, Santos JZ. Da ética ambiental à bioética ambiental: antecedentes, trajetórias e perspectivas. Hist Ciênc Saúde Manguinhos [Internet]. 2017 [acesso 20 ago 2020];24(2):391-409. DOI: 10.1590/s0104-59702017000200005

8. Conselho Federal de Medicina. Resolução CFM no 1.805, de 9 de novembro de 2006. Na fase terminal de enfermidades graves e incuráveis é permitido ao médico limitar ou suspender procedimentos e tratamentos que prolonguem a vida do doente, garantindo-lhe os cuidados necessários para aliviar os sintomas que levam ao sofrimento, na perspectiva de uma assistência integral, respeitada a vontade do paciente ou de seu representante legal. Diário Oficial da União [Internet]. Brasília, 28 nov 2006 [acesso 21 ago 2020]. Disponível: https://bit.ly/3hxOhVY

9. Conselho Federal de Medicina. Resolução CFM no 1.995, de 9 de agosto de 2012. Dispõe sobre as diretivas antecipadas de vontade dos pacientes. Diário Oficial da União [Internet]. Brasília, p. 269-70, 31 ago 2012 [acesso 28 ago 2020]. Seção 1. Disponível: https://bit.ly/32C24EP

10. Conselho Federal de Medicina. Código de Ética Médica: Resolução CFM no 2.217, de 27 de setembro de 2018, modificada pelas Resoluções CFM no 2.222/2018 e 2.226/2019 [Internet]. Brasília: CFM; 2019 [acesso 20 ago 2020]. Disponível: https://bit.ly/3gzOTsL

11. Cassell EJ. The nature of suffering and the goals of medicine. Nova York: Oxford University Press; 1991.

12. Rebelo C. Leitura de "Os três níveis do juízo médico" de Paul Ricoeur: a importância do juízo prudencial para o encontro terapêutico. Texto Aberto IEF [Internet]. 2018 [acesso 20 ago 2020];(2):1-12. Disponível: https://bit.ly/2YlfApn

13. Madrid R. La bioética de Tristram Engelhardt: entre la contradicción y la postmodernidad. Rev. bioét. (Impr.) [Internet]. 2014 [acesso 21 ago 2020];22(3):441-7. DOI: 10.1590/1983-80422014223026

14. Engelhardt HT Jr. Los fundamentos de la bioética. Barcelona: Paidós; 1995.

Tatiana Bragança de Azevedo Della Giustina - Doutora - tatiana.giustina@portalmedico.org.br (iD) 0000-0001-5905-4722

Rui Nunes - Doutor - ruinunes@med.up.pt

(iD) 0000-0002-1377-9899

\section{Bioética}

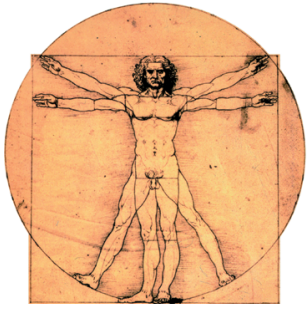

